UDC 930.26(470.45):726

Submitted: 07.09.2018

LBC 63.48(2P-4Bог)-427.1

Accepted: 24.10 .2018

\title{
ABOUT THE SOCIAL STATUS OF THE WOMAN FROM BARROW 34 OF THE KALINOVSKIY BURIAL MOUND ${ }^{1}$
}

\author{
Anatoliy S. Skripkin \\ Volgograd State University, Volgograd, Russian Federation
}

\begin{abstract}
The paper is devoted to determining the social status of a young woman buried in barrow 34 of the Kalinovskiy burial mound which is located on the left bank of the Volga river within the Volgograd region. The peculiarity of this burial is the presence of the armaments such as sword, arrowheads and horse harness. These items mark the lifetime status of this buried woman as a mounted warrior. The analysis of the funeral rite testifies to the rare cases of existence of armaments and the details of horse harness in female burials. Written sources of earlier time related to Sauromatian history testify to the participation of Sauromatian women in the military actions. According to the custom of that time, they were supposed to kill three enemies before getting married. This information can be regarded as a kind of initiation at transformation of a girl to the status of a married woman. Probably, such a rite was preserved in Sarmatian culture of the first centuries of the new era. This event can be confirmed by archaeological parallels, the burial rite, the Sauromatian and Middle Sarmatian material cultures, and in their similarity in anthropological data.
\end{abstract}

Key words: the Sarmatians, burial, barrow, Kalinovskiy burial mound, armament.

Citation. Skripkin A.S., 2018. About the Social Status of the Woman from Barrow 34 of the Kalinovskiy Burial Mound. The Lower Volga Archaeological Bulletin, vol. 17, no. 2, pp. 51-57. (in Russian). DOI: https://doi.org/ 10.15688/nav.jvolsu.2018.2.4

УДК 930.26(470.45):726

ББК 63.48(2Р-4Вог)-427.1

Дата поступления статьи: 07.09.2018

Дата принятия статьи: 24.10.2018

\section{О СОЦИАЛЬНОМ СТАТУСЕ ЖЕНЩИНЫ ИЗ КУРГАНА 34 КАЛИНОВСКОГО МОГИЛЬНИКА ${ }^{1}$}

\author{
Анатолий Степанович Скрипкин \\ Волгоградский государственный университет, г. Волгоград, Российская Федерация
}

\begin{abstract}
Аннотация. Статья посвящена определению социального статуса молодой женщины, погребенной в кургане 34 Калиновского могильника, располагавшегося на левом берегу Волги в пределах Волгоградской области. Особенностью этого погребения является наличие в нем предметов вооружения: меча и наконечников стрел, а также конской узды. Эти предметы маркируют прижизненный статус погребенной женщины как конного воина. Анализ погребального обряда сарматских захоронений свидетельствует о редких случаях нахождения в женских погребениях предметов вооружения, а также деталей конской упряжи. Письменные источники более раннего времени, относящиеся к савроматской истории, свидетельствуют об участии в ратных делах савроматских девушек. По обычаю того времени они должны были убить трех врагов, прежде чем выйти замуж. Эту информацию можно расценивать как своеобразную инициацию при переходе девушки в новый статус замужней женщины. Возможно, такой обряд сохранился и у сарматов первых веков новой эры. Это событие в определенной мере находит подтверждение в археологических параллелях, в обряде погребения и материальной культуре савроматских и среднесарматских племен, а также в их сходстве по антропологическим данным.

Ключевые слова: сарматы, погребение, курган, Калиновский могильник, вооружение.

Цитирование. Скрипкин А. С., 2018. О социальном статусе женщины из кургана 34 Калиновского могильника // Нижневолжский археологический вестник. Т. 17, № 2. С. 51-57. DOI: https://doi.org/10.15688/ nav.jvolsu.2018.2.4
\end{abstract}


Калиновский курганный могильник исследовался отрядом Сталинградской археологической экспедиции под руководством В.П. Шилова в течение трех лет (19521954 годы). В могильнике, который располагался на левом берегу Волги напротив районного центра Дубовка, были раскопаны 62 кургана [Шилов, 1959, с. 323-523].

В статье предпринимается попытка определения социального статуса женщины из кург. 34 этого могильника. Данное погребение было основным в небольшом кургане высотой 0,38 м и диаметром 8-12 метров. В кургане было еще одно разрушенное погребение ребенка, в котором найдены мелкие фрагменты лепного горшка.

Женское погребение было сооружено в подквадратной яме со сторонами $1,95 \times 1,75$ м и глубиной 1,75 метра. Положение костяка оказалось близким к диагональному, несколько сдвинутым к С3 углу. Погребенная была ориентирована головой на юго-запад, а ее череп - искусственно деформирован (рис. 1,1 ) [Шилов, 1959 , с. 390 , рис. 29,1$]$.

Определение пола и возраста погребенной в этом кургане было сделано В.В. Гинзбургом. Он охарактеризовал ее как женщину возмужалого возраста с искусственной деформацией черепа средней степени [Гинзбург, 1959, c. 562].

Интересен набор вещей, сопровождавших погребенную. Это двусоставные удила с псалиями, которые имели по две выступающие петли на каждой из них (рис. 1,2); свыше 60 железных трехлопастных черешковых наконечников стрел, помещенных в кожаный колчан (рис. 1,3); в области таза - круглая железная пряжка (рис. 1,4); у правого бедра железный меч с кольцевым навершием, общая длина которого 58 см (рис. 1,5).

По вещам и обряду погребения этот комплекс следует отнести к среднесарматскому времени, однако один из признаков - искусственная деформация головы - наиболее типичен для позднесарматского времени. Сам обряд погребения, в частности, положение погребенной по диагонали подквадратной ямы с ориентировкой головы на юго-запад, наиболее характерен для среднесарматской культуры, как и меч с кольцевым навершием, а также колчан с большим количеством нако- нечников стрел. В позднесарматских погребальных комплексах наконечники стрел встречаются крайне редко и в небольших количествах. Псалии с выступающими петлями наиболее характерны для сарматских памятников двух последних веков до н.э. Встречаются они и в памятниках среднесарматского времени [Мыськов и др., 1999, с. 155-156, рис. 5], в ряде случаев их находки известны и в позднесарматское время. В.П. Шилов отнес это погребение к группе среднесарматских, датировав их I в. до н.э. - I в. н.э. В настоящее время дата среднесарматской культуры изменена в сторону ее омоложения. Возможно, это погребение датируется первой половиной II в. н.э., в котором отмечен один из ранних случаев искусственной деформации головы. По ряду деталей обряда погребение калиновского кургана 34 близко погребению из кург. 11 у с. Старица в Астраханской области. Здесь в небольшом кургане в подквадратной яме находился женский костяк, также несколько сдвинутый от основной диагональной оси к северо-западному углу, с признаками искусственной деформации черепа. По наличию довольно выразительного материала, в том числе и импортного происхождения, В.П. Шилов, исследовавший Старицкий могильник, датировал погребение в кург. 11 первой половиной II в. н.э. [Шилов, 1968, с. 310-323].

Необычность этого женского погребения состоит в наличии предметов вооружения, меча и колчана со стрелами одновременно, а также деталей конской упряжи, что подчеркивает статус погребенной как конного воина.

В составленной ранее далеко не полной выборке среднесарматских погребений Нижнего Поволжья, включающей 160 комплексов, за исключением нескольких парных (мужчина + женщина) и детских погребений, мужские составляли 76 захоронений, женские - 56 (в 11 случаях с детьми). В женских погребениях, кроме кург. 34 Калиновского могильника, еще в одном комплексе был найден меч, в другом - наконечники стрел. Не отмечено ни одного случая нахождения в одном погребении меча и наконечников стрел одновременно, не были обнаружены и детали конской упряжи.

Существенно отличаются мужские погребения от женских в плане наличия в них 
предметов вооружения. Из 76 мужских погребений в 48 найдены мечи или кинжалы, в 35 наконечники стрел, мечи совместно с наконечниками стрел обнаружены в 21 погребении. Крайне редко в мужских погребениях находят детали конской упряжи: из всей выборки отмечено два таких случая.

Весьма редко предметы оружия встречаются и в раннесарматских женских погребениях II-I вв. до н.э., о чем свидетельствует специальное исследование, проведенное по материалам Нижнего Дона. Его результаты привели авторов к выводу, что «археологические данные не позволяют говорить о прослойке «военизированных» женщин в сарматском обществе этого периода» [Глебов, Толочко, 2016, c. 60].

Эти примеры свидетельствуют о том, что наличие предметов вооружения не характерно для женских захоронений последних веков до н.э. и первых веков н.э. и подтверждает тот факт, что основой воинского контингента сарматского общества являлись мужчины.

Сложной проблемой является определение социального статуса женского погребения из калиновского кургана 34. По погребальному обряду, учитывая небольшие размеры курганной насыпи, и по сопровождающим вещам к числу элитных его вряд ли можно относить. Меч, наконечники стрел это обычная находка в рядовых мужских захоронениях. Престижные погребения среднесарматского времени обычно отличаются набором дорогой посуды, предметов, выполненных в зверином стиле, они, как правило, сооружены под наиболее высокими курганными насыпями в могильниках. Например, в том же Калиновском могильнике было открыто богатое женское погр. 8 из кург. 55, в котором обнаружены различная металлическая посуда, чаша из стекла, золотые серьги, золотая гривна и браслеты. И хотя оно являлось впускным в насыпь более древнего кургана, но при этом было сооружено в самом большом кургане в могильнике высотой 2,6 м [Шилов, 1959, с. 402-404].

В плане рассматриваемой проблемы представляет интерес сообщение Псевдо-Гиппократа о женщинах савроматов, о которых он пишет следующее: «Их женщины ездят верхом, стреляют из луков и мечут дротики, сидя на конях, и сражаются с врагами, пока они в девушках; а замуж они не выходят, пока не убьют трех неприятелей, и поселяются на жительство с мужьями не прежде, чем совершат обычные жертвоприношения. Та, которая выйдет замуж, перестает ездить верхом, пока не появится необходимость поголовно выступать в поход» [Псевдо-Гиппократ, 1990].

Из фрагмента этого трактата следует, что савроматские женщины в молодом возрасте участвовали в сражениях. После замужества они прекращали заниматься военным делом и посвящали себя семейным делам, воспитывали детей и только в экстраординарных случаях выступали в поход. Возможно, в трактате Псевдо-Гиппократа преувеличена обязанность савроматских женщин в выполнении предбрачного обычая, здесь мог сказаться широко распространенный мифологический сюжет о происхождении савроматов от легендарных амазонок. Однако, вероятно, положение женщин до брака и после него у савроматов отличалось. Не исключено, что молодые женщины до замужества могли принимать более активное участие в военных делах, а убийство врага рассматривалось как элемент инициации, необходимость которого объяснялась переходом в новый социальновозрастной статус замужней женщины.

В.В. Гинзбург возраст погребенной женщины в кург. 34 определял как возмужалый ${ }^{2}$. Можно предположить, что и у сарматов начала нашей эры сохранялся обычай, который использовался в савроматском обществе.

Мной раньше отмечалось возрождение старых традиций, бытовавших в савроматское время в период формирования среднесарматской культуры. Это выражалось в увеличении погребений под индивидуальной насыпью, в распространении диагональных погребений, в появлении серии коротких мечей с волютообразным навершием, лепной керамики, типологически близкой савроматской, в положении каменных плит в погребения и целых зеркал [Скрипкин, 1992, с. 29]. В последнее время эти наблюдения подтвердились и при анализе антропологического материала. Л.Т. Яблонский отметил «антропологическое сходство “савроматов" и сусловцев, которое может свидетельствовать в пользу ге- 
A.S. Skripkin. About the Social Status of the Woman from Barrow 34 of the Kalinovskiy Burial Mound

нетических связей тех и других» [Яблонский, 2017 , с. 237]. Этот феномен пока не находит удовлетворительного объяснения по той причине, что между памятниками савроматского и среднесарматского времен существует значительный хронологический разрыв более чем в три века. Можно предположить, что в среднесарматское время происходит в какойто мере возрождение мировоззренческих представлений предшествующего времени, разделенных несколькими веками. Все это не исключает и сходство в возрастной регламентации женщин в савроматское и среднесарматское время. 


\section{ИЛЛЮСТРАЦИИ}

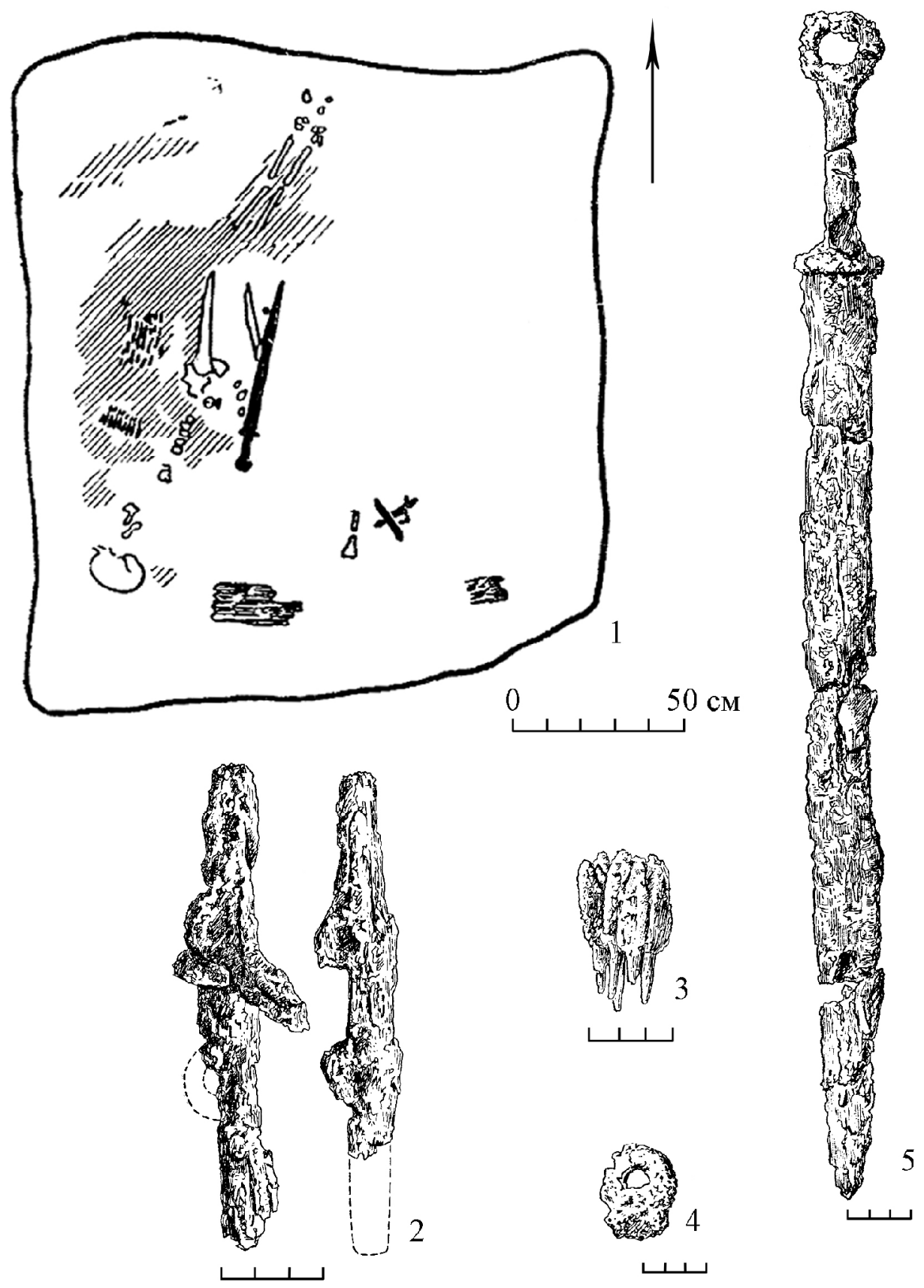

Рис. 1. Женское погребение из калиновского кургана 34 :

1 - план погребения; 2 - удила; 3 - наконечники стрел; 4 - пряжка; 5 - меч (2-5 - железо)

Fig. 1. The female burial from barrow 34 of the Kalinovskiy burial mound: 1 - plan of the burial; 2 - horse bit; 3 - arrowheads; 4 - buckle; 5 - sword (2-5 - iron) 


\section{ПРИМЕЧАНИЯ}

${ }^{1}$ Исследование выполнено при финансовой поддержке РФФИ и Администрации Волгоградской области в рамках научного проекта № 17-1134009-ОГН $\backslash 18$ «Элиты сарматского общества Волго-Донского региона (проблемы выделения и социальной интерпретации)».

2 Этим термином обозначали молодых людей в возрасте от 18 до 25 лет. Консультация д.и.н. М.А. Балабановой.

\section{СПИСОК ЛИТЕРАТУРЫ}

Гинзбург В. В., 1959. Этногенетические связи древнего населения Сталинградского Заволжья (по антропологическим материалам Калиновского могильника) // Материалы и исследования по археологии СССР. № 60. М. : Изд-во АНСССР. C. 524-594.

Глебов В. П., Толочко И. В., 2016. Женские погребения с оружием на Нижнем Дону в эпоху позднего эллинизма: Танаис и сарматы // Античная цивилизация и варварский мир Понто-Каспийского региона: материалы Всерос. научн. конф. с междунар. участием, посвящ. 70-летнему юбилею Б.А. Раева (Кагальник, 20-21 октября 2016 г.). Ростов н/Д : Изд-во ЮНЦРАН. С. 44-84.

Мыськов Е. П., Кияшко А. В., Скрипкин А. С., 1999. Погребение сарматской знати с Есауловского Аксая // Нижневолжский археологический вестник. Вып. 2. С. 147-167.

Псевдо-Гиппократ, 1990. О воздухе, водах и местности // Кавказ и Дон в произведениях античных авторов. Ростов н/Д : Русская энциклопедия. C. $61-67$.

Скрипкин А. С., 1992. Азиатская Сарматия. Проблемы хронологии, периодизации и этнополитической истории : научный доклад, представленный в качестве диссертации на соискание ученой степени доктора исторических наук. M. 46 c.

Шилов В. П., 1959. Калиновский курганный могильник // Материалы и исследования по археологии СССР. № 60. М. : Изд-во АН СССР. C. 323-523.

Шилов В. П., 1968. Позднесарматское погребение у с. Старица // Античная история и культура
Средиземноморья и Причерноморья. Ленинград : Наука. Ленинградское отделение. С. 310-323.

Яблонский Л. Т., 2017. На востоке скифской ойкумены. М. : Грифон. 400 с.

\section{REFERENCES}

Ginzburg V.V., 1959. Ethnogenetic Connections of the Ancient Population of the Stalingrad TransVolga Region (Based on Anthropological Materials of the Kalinovskiy Burial Mound). Materialy $i$ issledovaniya po arkheologii SSSR, no. 60. Moscow, Izd-vo AN SSSR, pp. 524-594.

Glebov V.P., Tolochko I.V., 2016. Female Burials with Weapons in the Lower Don Region in the Late Hellenistic Epoch: Tanais and the Sarmatians. Ancient Civilization and Barbaric World of the Ponto-Caspian Region. Proceedings of the All-Russian Scientific Conference with an International Component Dedicated to B.A. Raev's 70 ${ }^{\text {th }}$ Anniversary (Kagalnik, 20-21 October 2016). Rostov-on-Don, Izd-vo YuNTs RAN, pp. 44-84.

Myskov E.P., Kyashko A.V., Skripkin A.S., 1999. The Burial of Sarmatian Elite from the Esaulovsky Aksay River. The Lower Volga Archaeological Bulletin, iss. 2, pp. 147-167.

Pseudo-Hippocrates, 1990. On air, Water and Terrain. Kavkaz i Don v proizvedeniyakh antichnykh avtorov. Rostov-on-Don, Russian encyclopedia Publ., pp. 61-67.

Skripkin A.S., 1992. Asian Sarmatia. Problems of Chronology, Periodization and Ethnopolitical History: An Academic Report Presented as PhD Thesis. Moscow. $46 \mathrm{p}$.

Shilov V.P., 1959. The Kalinovsky Burial Mound. Materialy $i$ issledovaniya po arkheologii SSSR, no. 60, vol. 1. Moscow, Izd-vo AN SSSR, pp. 323-523.

Shilov V.P., 1968. The Late Sarmatian Burial near the Village Staritsa. Antichnaya istoriya i kultura Sredizemnomorya $i$ Prichernomorya. Leningrad, Nauka Publ., pp. 310-323.

Yablonsky L.T., 2017. On the East of the Scythian Populated Universe. Moscow, Grifon Publ. $400 \mathrm{p}$. 


\section{Information about the Author}

Anatoliy S. Skripkin, Doctor of Sciences (History), Professor of Department of Russian and Foreign History, Archaeology, Volgograd State University, Prosp. Universitetsky, 100, 400062 Volgograd, Russian Federation, anatoly.skripkin@volsu.ru, adsi@volsu.ru.

\section{Информация об авторе}

Анатолий Степанович Скрипкин, доктор исторических наук, профессор кафедры отечественной и всеобщей истории, археологии, Волгоградский государственный университет, просп. Университетский, 100, 400062 г. Волгоград, Российская Федерация, anatoly.skripkin@volsu.ru, adsi@volsu.ru. 